\title{
A Brief History of Listening Comprehension in Second Language Teaching and Learning
}

\author{
Mehrdad Nazarieh $\mathbb{D}^{1},{ }^{1}$ Mohammad Hasan Razmi $\mathbb{D}^{2},{ }^{2}$ Mahdieh Azizian $\mathbb{D}^{2}$, \\ and Muhammad Usman Ghani ${ }^{3}$ \\ ${ }^{1}$ Department of Foreign Languages, Kerman Institute of Higher Education, Kerman, Iran \\ ${ }^{2}$ Modeling in Health Research Center, Institute for Futures Studies in Health, Kerman University of Medical Sciences, \\ Kerman, Iran \\ ${ }^{3}$ Department of English, College of Science and Humanities, Prince Sattam Bin Abdulaziz University, Al Kharj, Saudi Arabia \\ Correspondence should be addressed to Mahdieh Azizian; m_azizian@kmu.ac.ir
}

Received 24 November 2021; Accepted 1 February 2022; Published 28 February 2022

Academic Editor: Ehsan Rezvani

Copyright (c) 2022 Mehrdad Nazarieh et al. This is an open access article distributed under the Creative Commons Attribution License, which permits unrestricted use, distribution, and reproduction in any medium, provided the original work is properly cited.

\begin{abstract}
Listening, as an overlooked aspect of a foreign language acquisition, was regarded as a passive procedure to be acquired by itself, during the early days of second language teaching. As the days of second language teaching were going by, the listening difficulties and problems ensued to get in the way of second language acquisition/learning. The automatic acquisition of listening comprehension seemed to be a failed assumption. The theorists and researchers in the field, consequently, came up with the idea of developing rigorous theories to initially redefine the listening process and furthermore set clear-cut and definite standards to help the learners improve their comprehension in a specific listening context. Looking at the listening comprehension with a new viewpoint, at a specific time in the history of second language acquisition, was not at a distance from the common views over learning and teaching at that time. Therefore, the prevailing views in a specific era exerted a powerful influence over the views on teaching listening comprehension skills. The theoretical definitions of listening comprehension along with a brief history of L2 listening comprehension from the very early days of second language teaching to the present time have been discussed in the subsequent sections.
\end{abstract}

\section{Introduction}

Listening is a multifaceted and active process and not the passive perception of spoken communication [1]. According to Rivers and Temperley ([2], p. 63), listening comprehension is "not a passive but an active process of constructing a message from a stream of sounds with what one knows of the phonological, semantic, and syntactic potentialities of the language." O'Malley et al. ([1], p. 418) defined listening comprehension as "an active process in which the individuals focus on selected aspects of aural input, construct meaning from passages, and relate what they hear to existing knowledge." For Vandergrift [3], listening is "A complex and active process in which the listener must discriminate between sounds, understand vocabulary, and grammatical structures, interpret stress and intonation, retain the data collected in the above processes, and interpret it within the immediate as well as the larger sociocultural context of the utterance" ([2], p. 168).

To put it in a nutshell, listening comprehension is a conscious and dynamic activity used by the learners to construct their own understanding by means of cognition and the existing contextual information. Abundant research has been conducted to demonstrate the substantial role of listening comprehension in language pedagogy; in this regard, Dunkel [4] stated that the study of listening comprehension has become the center of attention in second language acquisition theory building, teaching, and research. 


\section{The Listening Process}

As stated by Lynch [5], listening is a continuing process of constructing and modifying an interpretation of what a specific text in a particular situation is about, based on whatever information seems pertinent at the time. The listener, as a result, takes the incoming data by means of the acoustic signals and, making use of a great variety of knowledge, interprets the incoming data for a specific communicative purpose. Listening is a recurrently used mode of communication in each communicative event.

Subsequently, listening has appeared as a significant and indispensable constituent of language pedagogy to foster facilities for the language learners to maximize their development in the transmission of reciprocal information in a speech event and make the appropriate communication based on that.

\section{A Brief History of Listening Comprehension}

Listening, as a major language skill that naturally develops faster than speaking and influences the development of reading and writing skills in a new language [6], was not brought into prominence until the late 1940s [7]. Listening, at that time, was defined according to successful transmission and recreation of messages. The problem with such a view was that listening would suffer from the assumption that exposure to language would lead to mastery in the acquisition of language listening skills [8].

Through the 1960s and in the wake of the influence of behaviorism on language learning, listening was defined as analyzing and classifying input, so that it could be stored and retrieved efficiently. Perception and decoding of the sounds phonemes, word stress, and sentence-level intonation were all the focus of instruction back then. The main listening activities included drills for discriminating sounds at word and sentence levels on the basis of a linear processing of information [9]. Language learning was regarded as a near mechanical response to stimuli. Students were considered limited in the development of their comprehension and memory capabilities. While speaking, reading, and writing received direct instructional attention, learners were regularly expected to develop their listening skill through a process of osmosis and without any assistance $[10,11]$. In the osmosis approach which is also recognized as the audiolingual method, it is supposed that if learners listen to the target language consistently, they will be able to improve their listening comprehension skill through such an experience [12]. Consequently, during the 1960s, listening was deeply under the influence of productive skills pedagogy [13].

In the 1970s and 1980s, definition of listening is interpreting the cultural significance of speech behavior earned acceptance. The interactionist and sociolinguistic movements were the main theoretical paradigms of learning and comprehension [9]. The instructional focus, in the realm of listening, was on practicing listening skills based on responding to spoken texts in socially and contextually appropriate ways. The authentic recordings, face-to-face learner talk, and expert speaker-learner interaction were used as the input instruments at that time [9]. In 1975, scholars such as Rubin and Stern suggested that rather than simply having an ear or inherent ability for language learning, some decent language learners might be applying strategies that bring about second or foreign language acquisition.

It was then in the 1990s when listening came to be labeled as the parallel processing of input. Krashen's [14] views of comprehensible input (that later on were projected in Asher's [15] total physical response) gained momentum at that time. Besides, with the arrival of communicative language teaching (CLT) methodology and an emphasis on listening as a frequently used mode of human communication, a need for teaching language listening skills was deeply felt. With the advent of social-cognitive models of comprehension, along with the existing interactionist and sociolinguistic paradigms of comprehension, the use of listening strategies for enhancing comprehension and coping with problems came into fashion [9].

From the 1990s afterwards, some models have been presented to describe the nature of listening comprehension. The theoretical foundations are presented in the following entries.

\section{Anderson's Three Stages of Listening Comprehension}

Anderson [16] suggested three interconnected and recursive processes to explain listening comprehension: perceptual processing, parsing, and utilization. Anderson presented his model in 1985 [16]. The perceptual processing was relying on attention to the sounds that were temporarily stored in echoic memory [1]. In this stage, the listeners' role was to pay attention to potentially meaningful sounds, keywords which lead them to meaning construction, and contextual information which assisted in the interpretation of meaning [17].

In the parsing stage, the listeners transformed the incoming words into meaningful mental representations to be retained in short-term memory (STM). According to Bacon [17], a number of factors such as quality of the input, linguistic knowledge, and topic familiarity could influence the nature of the processing unit.

In the utilization stage, the listeners make an association between the incoming oral input and the existing knowledge already stored in long-term memory (LTM) to construct meaning. According to O'Malley et al. [1], the background knowledge exists in the form of schemata, propositions, and interrelated concepts. The seemingly dormant knowledge retained in LTM was known to be activated in this stage, so that the incoming information could be transformed in a way that interpretation of comprehension was guaranteed [17].

\section{McLaughlin et al.'s Attention Processing Model}

Movement towards a cognitive outlook of foreign or second language acquisition became evident in the attention processing approach formulated by McLaughlin et al. [18]. In this model, the learner was viewed as an active organizer of 
information. In a listening task, the learners were considered to actively impose cognitive schemata on the incoming data to organize the meaning. According to O'Malley and Chamot [19], the extent of cognitive involvement was influenced by the interaction between the task requirements and the mental processes used by the learner. McLaughlin, et al.'s [18] model was composed of two main categories, namely, the attention category and the processing category.

The attention category included focal and peripheral attention. In other words, attention was paid to both the main idea of the incoming message and to the other characteristics of the message such as the accent of the speaker almost simultaneously. The processing category included the controlled and automatic processing. Compared with the temporariness nature of controlled processing, the automatic processing was regarded as the permanent process [18].

In this model, restructuring played a vital role in facilitating ways by which the controlled processing could gradually proceed to the automatic processing. Restructuring in McLaughlin et al.'s [18] model referred to "the components of a task are coordinated, integrated, or reorganized into new units" ([20], p. 300). Such components were known to have the capability to replace the older ones to automate the listening comprehension.

\section{Bialystok's Model of Explicit and Implicit Knowledge}

In 1978, Bialystok proposed the explicit and implicit knowledge model to explain second language learning. This model included three levels: input, knowledge, and output. Listening comprehension, in this model, was considered in a way that at first, language should undergo an experience. In other words, learners should be exposed to the aural input. The second level (i.e., knowledge level) explained how the incoming information could be stored in three forms of explicit linguistic knowledge, implicit linguistic knowledge, and other knowledge. By explicit linguistic knowledge, Bialystok [21] meant the knowledge about the particularities of language such as syntactic rules, vocabulary use, and pronunciation rules. Implicit linguistic knowledge referred to the "intuitive information upon which the language learner operates" ([21], p. 72) in order to construct meaning in a listening task. According to Bialystok, the distinction between the explicit and implicit linguistic knowledge lay in the function rather than the content of the incoming data.

Explicit knowledge, in this model, was serving three main functions, namely, a shield for the new incoming information, the storage for the explicitly represented information, and an explicit system of articulation. The implicit knowledge, on the other hand, had the only function of being a working system which included all the information about the target language. Listeners were considered to be able to transfer explicit knowledge to implicit knowledge through learning strategies. In this model, other knowledge included the relevant but not linguistic knowledge that the learners brought to a certain listening task.
The last level in Bialystok's [21] model (i.e., output) was more of an explanation for second language learning in other areas of language learning than the listening skill. Needless to say, the prosperity of this last level by means of listening tasks could definitely influence other productive skills [6] at least in an indirect way.

\section{Nagle and Sanders' L2 Listening Comprehension Model}

Nagle and Sanders [22] formulated the first model of listening comprehension in the adult learner. In their opinion, the language comprehension process, until that time, had been assumed generally on the basis of second language acquisition/learning. Therefore, they proposed a model that specifically and exclusively explained the listening comprehension.

Nagle and Sanders [22] made proper use of Krashen's [14] views, Bialystok's [21] second language learning model, and McLaughlin et al.'s [18] attention processing view of second language learning. In Nagle and Sanders' [22] perspective, comprehension both added to and drew upon learning in a reciprocal way. According to this model, the listeners constructed meaning through the combination of prior knowledge retrieved from long-term memory and the incoming new information in a listening task.

\section{Current Understanding of Listening Comprehension}

The current advancements in the area of L2 listening comprehension owes much to the efforts made by aforementioned scholars in the field such as Anderson [16], McLaughlin et al. [18], Bialystok [21], and Nagle and Sanders [22]. However, looking back over the 20 years, it can be ascertained how the focus on L2 listening comprehension has changed. More recently, the role of strategy training has been evident in changing the course of L2 listening comprehension [9]. The significance of strategy training in L2 comprehension lies in three research-based conclusions: the frequency and type of the used strategies distinguishes successful from unsuccessful learners [23], learning strategies can be trained [24], and the use of strategies can be shown to enhance language learning [1]. According to Anderson [16], second language learning strategies do not seem to differ from general strategies used in other skills such as problem solving and reading.

In line with the current new advancements in listening strategy training movements, some researchers such as Lynch [5], Vandergrift [3], and Macaro et al. [25] have drawn their attention to new evidence-based approaches in L2 listening comprehension training [9]. The approaches of the kind are based on the developments in linguistics and cognitive psychology. One of these approaches is the metacognitive approach proposed by researchers such as Mendelsohn [26] and Vandergrift [3]. The present study has used Vandergrift's [3] model as the theoretical framework of the investigation. It was in 2004 when a metacognitive cycle was proposed by Vandergrift to aid the learners make use of 
strategies in a listening task. At certain stages, the listeners were encouraged to use strategies in order to regulate their listening comprehension. This cycle encompassed some important metacognitive processes such as verification and evaluation that successful learners effectively use. The benefits of the cycle were twofold. First, these processes raised the awareness of the learners. Second, they provided the involved learners with the needed scaffolding while involving themselves in a listening task. Such a cycle would help the learners to increase their motivation and be more successful in other listening tasks [9]. Although this proposed cycle had its own merits, it was not without its challenges. As stated by Goh [9], one of the major limitations of the cycle was that it would not remain accountable outside the restricted walls of the classroom. In order to overcome such limitations, Vandergrift along with Goh, Mareschal, and Tafaghodtari in 2006 revised and expanded the cycle to involve the learners in a more widespread range of metacognitive activities [27]. What they proposed was deepening learners' understanding of themselves as L2 listeners and the demands of L2 listening thorough different metacognitive listening activities. Besides, they stated that the learners should be able to manage their comprehension through practicing such activities.

There is a growing trend in applying cutting-edge personality attributes and psychological findings to research into second language listening comprehension research. The individual differences and complex dynamic systems theory (CDST) are among the leading approaches to understand the mechanisms underlying learners' listening comprehension in a second language. Building on the tenets of the CDST, Razmi et al. [28] studied listening comprehension through the lens of individual differences research. Utilizing a multicategorical multiple mediation analysis, the authors probed the links among self-efficacy, perfectionism, and listening comprehension. This unique line of research can present new avenues for investigations into second language acquisition considering the individual differences as well as psychological aspects governing students' language learning. This study intends to give impetus for further research in this regard.

\section{Data Availability}

The data used to support the findings of this study are included within the article.

\section{Conflicts of Interest}

The authors declare that they have no conflicts of interest.

\section{References}

[1] J. M. O’Malley, A. U. Chamot, and L. Küpper, "Listening comprehension strategies in second language acquisition," Applied Linguistics, vol. 10, no. 4, pp. 418-437, 1989.

[2] W. Rivers and M. Temperley, A Practical Guide to the Teaching of English, Oxford, New York, NY, USA, 1978.

[3] L. Vandergrift, "Listening to learn or learning to listen?" Annual Review of Applied Linguistics, vol. 24, pp. 3-25, 2004.
[4] P. Dunkel, "Listening in the native and second/foreign language: toward an integration of research and practice," Tesol Quarterly, vol. 25, no. 3, pp. 431-457, 1991.

[5] T. Lynch, Communication in the Language Classroom, Oxford University Press, Oxford, UK, 1996.

[6] R. Scarcella and R. Oxford, The Tapestry of Language Learning: The Individual in the Communicative Classroom, Heinle and Heinle, Boston, MA, USA, 1992.

[7] C. M. Feyten, "The power of listening ability: an overlooked dimension in language acquisition," The Modern Language Journal, vol. 75, no. 2, pp. 173-180, 1991.

[8] J. Richards and W. Renandya, Methodology in Language Teaching: An Anthology of Current Practice, Cambridge University Press, New York, NY, USA, 2002.

[9] C. Goh, "Metacognitive instruction for second language listening development," RELC Journal, vol. 39, no. 2, pp. $188-213,2008$.

[10] D. Mendelsohn, "There ARE strategies for listening," TEAL Occasional Papers, vol. 8, pp. 63-76, 1984.

[11] R. L. Oxford, "Use of language learning strategies: a synthesis of studies with implications for strategy training," System, vol. 17, no. 2, pp. 235-247, 1989.

[12] M. E. Call, "Auditory short-term memory, listening comprehension, and the input hypothesis," Tesol Quarterly, vol. 19, no. 4, pp. 765-781, 1985.

[13] G. Brown, "Twenty-five years of teaching listening comprehension," English Teaching Forum, vol. 25, no. 1, pp. 11-15, 1987.

[14] S. Krashen, Principles and Practice in Second Language Acquisition, Pergamon, Oxford, UK, 1982.

[15] J. Asher, Learning Another Language through Actions: The Complete Teacher's Guidebook, Sky Oaks Production, Los Gatos, CA, USA, 3rd edition, 1988.

[16] J. R. Anderson, Cognitive Psychology and Its Implications, W. H. Freeman, New York, NY, USA, 4th edition, 1995.

[17] S. M. Bacon, "Phases of listening to authentic input in Spanish: a descriptive study," Foreign Language Annals, vol. 25, no. 4, pp. 317-333, 1992.

[18] B. McLaughlin, T. Rossman, and B. McLeod, "Second language learning: an information-processing perspective 1," Language Learning, vol. 33, no. 2, pp. 135-158, 1983.

[19] J. M. O'Malley and A. U. Chamot, Learning Strategies in Second Language Acquisition, Cambridge University Press, Cambridge, UK, 1990.

[20] D. Brown, Principles of Language Learning and Teaching, Pearson Education, White Plains, NY, USA, 5th edition, 2007.

[21] E. Bialystok, "A theoretical model of second language learning 1," Language and Learning, vol. 28, no. 1, pp. 69-83, 1978.

[22] S. J. Nagle and S. L. Sanders, "Comprehension theory and second language pedagogy," Tesol Quarterly, vol. 20, no. 1, pp. 9-26, 1986.

[23] J. M. O’Malley, A. U. Chamot, G. Stewner-Manzanares, L. Küpper, and R. Russo, "Learning strategies used by beginning and intermediate ESL students," Language Learning, vol. 35, pp. 21-46, 1985.

[24] A. U. Chamot, J. M. O’Malley, L. Küpper, and M. ImpinkHernandez, A Study of Learning Strategies in Foreign Language Instruction: First Year Report, Interstate Research Associates, Rosslyn, VA, USA, 1987.

[25] E. Macaro, S. Graham, and R. Vanderplank, "A Review of listening strategies: focus on sources of knowledge and on success," in Language Learner Strategies: 30 Years of Research and Practice, E. Macaro and A. Cohen, Eds., pp. 165-185, Oxford University Press, Oxford, UK, 2007. 
[26] D. J. Mendelsohn, “Teaching listening," Annual Review of Applied Linguistics, vol. 18, pp. 81-101, 1998.

[27] L. Vandergrift, C. C. M. Goh, C. J. Mareschal, and M. H. Tafaghodtari, "The metacognitive awareness listening questionnaire: development and validation," Language Learning, vol. 56, no. 3, pp. 431-462, 2006.

[28] M. H. Razmi, A. A. Jabbari, and A. M. Fazilatfar, "Perfectionism, self-efficacy components, and metacognitive listening strategy use: a multicategorical multiple mediation analysis," Journal of Psycholinguistic Research, vol. 49, no. 6, pp. 1047-1065, 2020. 